\title{
REVIEW
}

\section{Impact of adult growth hormone deficiency on metabolic profile and cardiovascular risk}

\author{
Lara Giovannini $^{1{ }^{*}}$, Giacomo Tirabassi ${ }^{1)^{*}}$, Giovanna Muscogiuri ${ }^{2)}$, Carolina Di Somma ${ }^{3)}$, \\ Annamaria Colao $^{2)}$ and Giancarlo Balercia ${ }^{1)}$ \\ 1) Division of Endocrinology, Department of Clinical and Molecular Sciences, Umberto I Hospital, School of Medicine, \\ Polytechnic University of Marche, Ancona, Italy \\ 2) Department of Clinical Medicine and Surgery, Section of Endocrinology, University "Federico II", Naples, Italy \\ 3) IRCCS SDN, Napoli Via Gianturco 113, Naples 80143, Italy
}

\begin{abstract}
Adult growth hormone deficiency (GHD) is a well defined clinical condition, which is characterized by abnormal body composition, impaired physical activity and decreased quality of life. In addition, in recent years, growing interest has been shown towards cardiovascular risks in adult patients affected by GHD. In this regard, GHD is widely known to be associated with increased mortality, likely due to the increase of risk factors, such as central obesity, impaired lipid and glucose profiles and other less-known risk factors, such as inflammatory cytokines, endothelial dysfunction and oxidative stress. However, very few papers have recently discussed this topic. In this review, the aim is to clarify this issue by discussing evidence regarding the effects of adult GHD on metabolic and cardiovascular profiles.
\end{abstract}

Key words: Growth hormone, Deficiency, Cardiovascular risk factor, Pituitary, Hormonal treatment

GROWTH HORMONE DEFICIENCY (GHD) in adults is a well-defined clinical condition, characterized by abnormal body composition, impaired physical activities as well as decreased quality of life; in addition, in recent years, growing interest has been shown towards cardiovascular risk in adult patients affected by GHD [1-9]. In light of the scantiness of recent specific reviews on this subject, in this paper we review the evidence of the metabolic and cardiovascular effects of GHD on adult patients.

\section{Diagnosis of GHD: a brief overview}

Three groups of adults affected by GHD have been included in the studies:

1) Patients with a previous diagnosis of childhood GHD (CO-GHD);

Submitted Jun. 19, 2015; Accepted Aug. 11, 2015 as EJ15-0337 Released online in J-STAGE as advance publication Aug. 21, 2015 Correspondence to: Giancarlo Balercia, M.D., Division of Endocrinology, Department of Clinical and Molecular Sciences, Via Conca 71, Umberto I Hospital, Polytechnic University of Marche, 60126 Ancona, Italy. E-mail: g.balercia@univpm.it *L.G. and G.T. equally contributed to this work and share the role of first author.
2) Patients with GHD caused by trauma or structural lesions at hypothalamic-pituitary level;

3) Patients affected by idiopathic GHD (very rare).

2011 Endocrine society guidelines recommend to evaluate as potentially affected by acquired GHD every adult who is either affected by hypothalamic-pituitary diseases or who has undergone surgery or irradiation in these regions or who has suffered from head trauma or even with biochemical evidence of pituitary hormone deficiency [10]. Diagnosis is made on the basis of stimulus tests, such as insulin tolerance test (ITT) and GH releasing hormone (GHRH) + arginine test (Table 1). However, it must be remembered that biochemical criteria for the diagnosis of adult GHD does not envisage age-, sex-, and body mass index (BMI)-specific cutoffs; in addition, a certain degree of variability exists both in assay methods and in stimulus test protocols. According to a multicenter study, which used a sensitive, immunochemiluminescent two-site assay, the GH values of $5.1 \mu / \mathrm{L}$ for the ITT and $4.1 \mu / \mathrm{L}$ for GHRHarginine test had sufficient specificity and sensitivity for the diagnosis of adult GHD [11]. Moreover, many European studies have proposed to adjust the cutoffs for GHRH + arginine test depending on BMI values. 
Table 1 Diagnosis of adult GHD

\begin{tabular}{|c|c|}
\hline Adult GHD & Diagnostic tests \\
\hline $\begin{array}{l}\text { Patients with CO-GHD due to genetic mutation, embriogenetic lesions } \\
\text { or irreversible damage of hypothalamus-pituitary system causing at } \\
\text { least } 3 \text { or more hormonal deficits }\end{array}$ & - Not required \\
\hline $\begin{array}{l}\text { - Patients with acquired GHD (head injury, hypothalamus-pituitary } \\
\text { system disorders, irradiation or surgery of these regions) having less } \\
\text { than } 3 \text { pituitary hormonal deficits }\end{array}$ & $\begin{array}{l}\text { - GHRH + Arginine test or insulin tolerance test } \\
\text { Glucagon test }\end{array}$ \\
\hline \multicolumn{2}{|l|}{ - Patients with idiopathic GHD } \\
\hline - Patients with idiopathic and isolated CO-GHD & - Gold standard: GHRH + Arginine test \\
\hline
\end{tabular}

In particular, Corneli et al. showed that the appropriate cut-points for diagnosing GHD were $11.5 \mu / \mathrm{L}$ for those with a BMI less than $25 \mathrm{~kg} / \mathrm{m}^{2}, 8.0 \mu / \mathrm{L}$ for a BMI of $25-30 \mathrm{~kg} / \mathrm{m}^{2}$, and $4.2 \mu / \mathrm{L}$ for those with a BMI greater than $30 \mathrm{~kg} / \mathrm{m}^{2}$ [12]. However, when GHRH is not available and ITT is either contraindicated or not practicable, the glucagon stimulation test can be useful for diagnosing GHD. When the glucagon test is used, a cut-point of between 2.5 and $3 \mu / \mathrm{L}$ has been shown to have adequate specificity and sensitivity for the diagnosis of GHD [10] (Table 1).

\section{Metabolic effects}

\section{1.a Glucose metabolism and insulin resistance}

GHD is often associated with impaired glucose metabolism, characterised by insulin resistance and fasting hyperinsulinemia $[6,13]$. Recently, the KIMS (Pfizer International Metabolic Database) study, which was carried out in 6050 GHD patients who were not undergoing the relevant replacement therapy, showed an increased prevalence of type 2 diabetes mellitus, especially in women, mainly due to increased BMI and to the impaired body composition; furthermore, $9.5 \%$ of nondiabetic patients presented glycated haemoglobin (HbA1c) values between 6 and 6.5\% [14]. The increased prevalence of type 2 diabetes in patients with $\mathrm{GH}$ deficiency is likely due to the increased insulin resistance, particularly at hepatic level, and to the inadequate beta cell ability to counteract insulin resistance $[15,16]$. However, the effects of GH replacement therapy on glucose metabolism are controversial. Bramnert et al. evaluated the effects of GH replacement therapy in 19 GHD patients after 1 week and after 6 months of treatment [17]. Hormone therapy induced an impaired insulin-induced glucose uptake after one week $(-52 \% ; P$
$=0.008)$ and after six months $(-39 \% ; P=0.008)$, which correlated with deterioration of glucose tolerance $(\mathrm{r}=$ $-0.481 ; P=0.003)$. Therefore, that report highlighted that both reduced glucose uptake and impaired glucose metabolism are associated with increased lipid oxidation due to lipolitic GH action. A worsening of glucose metabolism has also been observed in other studies with a follow-up of 12 months [18, 19]. However, in this regard, it is worth mentioning that duration of therapy may represent a confounding factor. A study evaluating 14 GHD patients, who were treated with hormone replacement therapy and evaluated every 3 months for 5 years, showed that glycemia and fasting insulin as well as homeostasis model assessment-estimated insulin resistance (HOMA-IR) index did not change significantly, whereas, after two years of GH replacement therapy, an improvement of glycaemia levels after oral glucose tolerance test was observed [20]. An improvement of oral glucose tolerance test was confirmed also by a work conducted on 22 subjects who were undergoing GH replacement therapy for about ten years [21]. A recent monocentric, prospective and open-label report by Elborsson et al. evaluated 156 hypopituitary GHD subjects undergoing GH replacement therapy for about fifteen years [22]. Fasting glycemia rose from 4.4 to $4.8 \mathrm{mmol} / \mathrm{L}$ during the study period $(P<0.001)$, whereas HbA1c improved from 5.0 to $4.6 \%(P<0.001)$. In conclusion, results on this subject are controversial. However, GH replacement therapy seems to exert a biphasic action. In the initial phase, a deterioration of glucose metabolism probably occurs due to decreased peripheral uptake of glucose, whereas, in the long term, low dosage of GH therapy leads to improved glycemia and insulin levels, likely due to a variation of body composition (Fig. 1) [23]. 


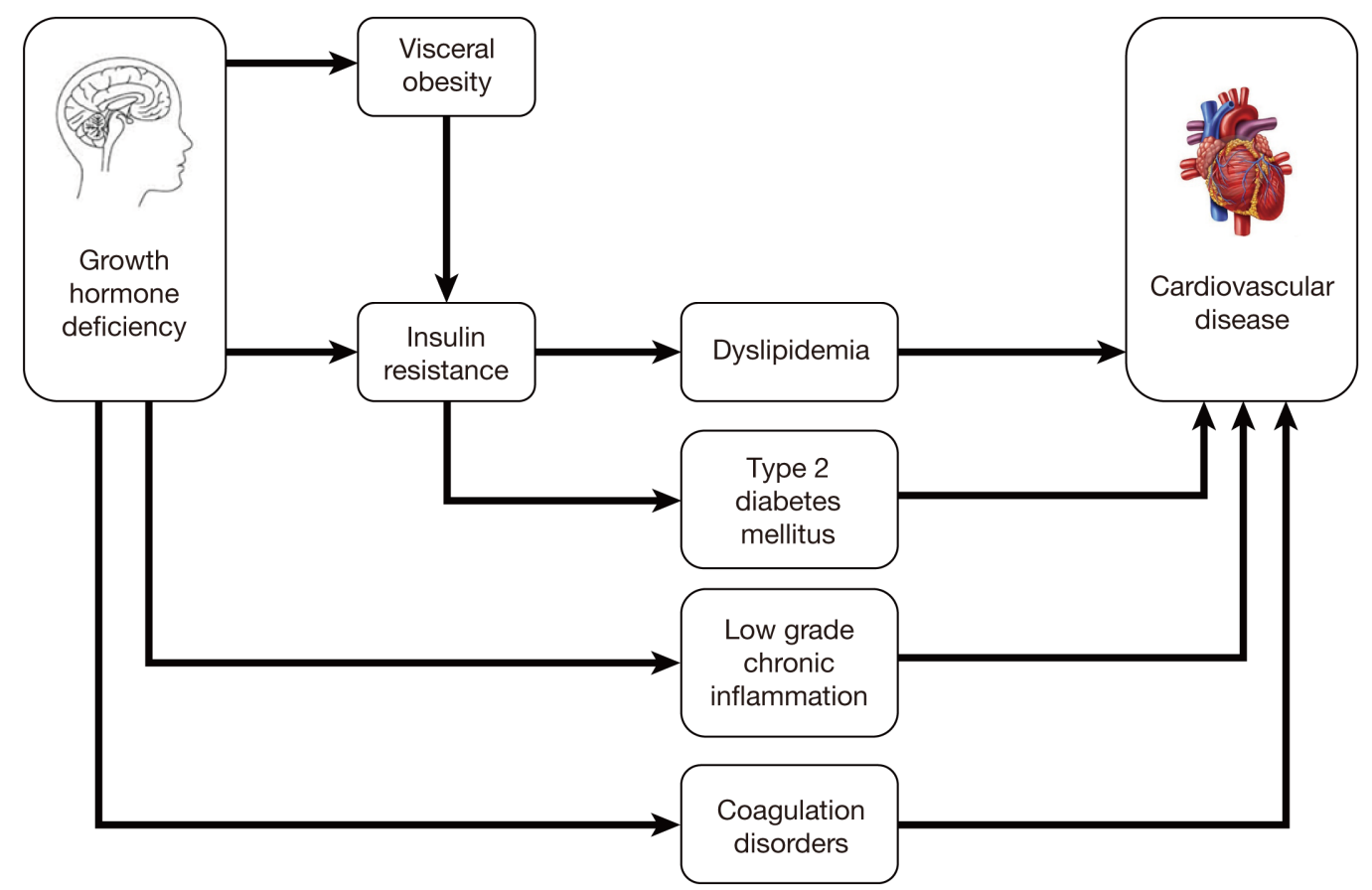

Fig. 1 Growth hormone deficiency and cardiovascular risk. Growth hormone deficiency has been associated with an increase of cardiovascular risk, due to an impairment of body composition, especially in visceral adipose tissue, and subsequent insulin resistance. Growth hormone deficiency has also been associated with glucose metabolism impairment, dyslipidemia, coagulation disorders and chronic inflammation, which globally concur to the increase of cardiovascular risk.

\section{1.b Lipid metabolism}

It is well-proven that the increase of low density lipoprotein (LDL) cholesterol and abdominal fat together with the decrease of high density lipoprotein (HDL) cholesterol can augment cardiovascular mortality and morbidity [24]. Lipid serum concentration strictly depends on production and clearance of apolipoprotein (apo) B contained in very low density lipoprotein (VLDL) and lipid metabolism is linked to the one of VLDL apo B, as they are precursors of intermediate density lipoprotein (IDL) and LDL apo B. Several lipid metabolism disorders, which lead to the early onset of atherosclerosis, are caused by hepatic hyperproduction of VLDL apo B [25].

GHD patients usually show increased levels of total and LDL cholesterol [26, 27], whereas more controversial results have been found regarding triglycerides and HDL $[7,28]$. A study by Abdu et al. evaluated lipid profile and cardiovascular risk by the Framingham score equation in GHD patients and age- and sex-matched controls [29]. That study showed, in both sexes, the increase of total/HDL cholesterol ratio, LDL cholesterol and the reduction of HDL cholesterol (especially in women), thus theoretically explaining the increase of cardiovascular risk in GHD patients.

It has been recently demonstrated that small dense LDL (sdLDL) is an independent cardiovascular risk factor and a report by Rizzo et al. found a greater presence of sdLDL in GHD patients [30].

As far as triglyceride metabolism is concerned, an important paper has evaluated the effects of acute GHD induced by pegvisomant [31]. In those subjects, it was observed that pegvisomant treatment alone increased serum triglycerides, thus suggesting a key-role of GH in triglyceride metabolism regulation. Other studies have demonstrated the association between GH and triglycerides; of note, a reduction of triglycerides after recombinant IGF-1 therapy has been observed [32], as well as an opposite correlation between insulinlike growth factor-1 (IGF-1) and triglycerides levels in elderly subjects [33]. Long-term GH replacement therapy (5-10 years) can lead to an improvement of lipid profile. Gotherstrom et al., in a prospective and monocentric study, demonstrated the decrease of total cholesterol and increase of HDL after a 5-year therapy in 118 GHD patients [34]. Similar results have also been obtained in other prospective and monocentric studies $[35,36]$, where after 7 years of GH replacement ther- 
apy an improvement of total and LDL cholesterol was evident, although no effect was observed on triglyceride levels. This finding was confirmed also in a recent prospective and long term study (15 years) conducted on 156 hypopituitary patients [22]. The neutral effect on triglyceride levels has also been observed in a metaanalysis which considered 37 blinded, randomized placebo-control trials involving adult patients undergoing GH replacement therapy; at the same time the positive effect on total and LDL cholesterol was confirmed [37] (Fig. 1).

\section{1.c Body composition}

Although the main peripheral targets of GH are represented by bone and muscle, GH is also able to promote lipolysis. Patients with isolated GHD have more abundant fat stores than healthy subjects because of the greater volume of adipose cells [38, 39]. Therefore, the impaired body composition results in a prevalent central fat distribution due to visceral fat accumulation with consequent increase of cardiovascular risk. In fact, low IGF-1 levels determine the increase of fat mass and the decrease of lean mass. Many studies have aimed to clarify this aspect. Various investigators demonstrated that fat mass was higher by around $7 \%$ in GHD patients compared with age, sex and height adjusted predicted values [40]. Similarly, Attanasio et al. found that metabolic syndrome prevalence was increased in GHD patients [41].

An observational monocentric study by Ukropec et al. which evaluated 16 GHD patients and 16 healthy subjects, reported that GHD patients with BMI of approximately $23 \mathrm{~kg} / \mathrm{m}^{2}$ had higher values of waist circumference and visceral fat compared to controls [42]. Another recent monocentric work conducted on 23 adult patients with congenital GHD who were evaluated by (dual-energy x-ray absorptiometry) DEXA, showed that these patients had a greater amount of abdominal and visceral fat than healthy subjects [43].

As far as the effects of GH replacement therapy are concerned, two different double blind, randomized, placebo controlled trials carried out in $\mathrm{GH}$-treated men and women reported a significant decrease of total body and trunk fat and an increase of lean body mass over baseline $[37,44]$. The reduction of waist/hip ratio has also been demonstrated by several prospective monocentric studies, which found an improvement of body composition especially in elderly GHD patients ( $>65$ years) compared to the younger ones [45-47]. Furthermore, a recent work assessing GHD patients under 15 years-replacement therapy reported a 3\% increase of lean mass compared to baseline [22] (Fig. 1).

\section{Inflammatory markers and cardiovascular risk}

C-reactive protein (CRP) is a well-known cardiovascular risk factor [48]. Both normoweight and obese GHD patients have a 4-5 fold increase of CRP levels, testifying the presence of a proinflammatory state [49]. Sesmilo et al. found an inverse correlation between CRP and IGF-1 levels in hypopituitary women affected by GHD [50] and Deepak et al. demonstrated an improvement of inflammation indexes, especially high sensitivity CRP, after 6 months of GH replacement therapy in 15 adult GHD patients (11 males) [51]. Similarly, pro-inflammatory cytokines, especially interleukin 6 (IL-6) and tumor necrosis factor- $\alpha$ (TNF$\alpha$ ), play a role in the increase of cardiovascular risk of GHD mainly in consequence of their effect on endothelium $[52,53]$. Of note, adipokines, peptides secreted by adipose tissue which also have endocrine, paracrine and autocrine actions are worthy of consideration [52, 53]. Circulating adipokines are represented by adiponectin, which has anti-inflammatory, antiatherogenic and insulin-sensitizing effect and by leptin which has instead prothrombotic, atherogenetic, prooxidative and angiogenetic actions as well as hypertrophic effect on smooth muscle [54].

In GHD patients, an increase of IL-6 levels has been reported, independently of BMI, and of TNF- $\alpha$ values, which decreased after GH replacement therapy $[55,56]$. Some Authors have demonstrated an increase of leptin values in GHD patients $[57,58]$. The relationship between increased levels of leptin and GHD has been observed in clinical trials involving subjects undergoing hormonal replacement therapy. In fact, some Authors reported that the increase of IGF-1 to normal values resulted in a reduction of circulating leptin levels [59].

GHD patients suffer from coagulation factors disorders such as the increase of Plasminogen activator inhibitor-1 (PAI) levels, fibrinogen and VIII factor [6062]. Thrombosis risk is very high, thus further increasing cardiovascular morbidity and mortality risk [61]. Of note, it has been observed that PAI-1 and fibrinogen levels decrease after GH therapy [63] and a normalization of impaired fibrinolysis after treatment of GHD has 
been confirmed also in a recent work by Miljic et al. [64]. Even the activity of protein S, which is decreased in GHD patients, is normalized by the therapy [65]. In fact, Cakir et al. evaluated 19 GHD patients both before and after 6 months of GH replacement therapy [65]. After treatment, a decrease of protein $\mathrm{S}$ levels compared to basal and to placebo controls was found in GHD patients; also a reduction of Antithrombin III (ATIII) and C protein was evident. Further studies will be needed in order to evaluate the effectiveness of GH treatment in decreasing cardiovascular risk in GHD. Moreover, it has been shown that values of pregnancy-associated plasma protein A (PAPP-A), a metalloproteinase secreted by artery smooth muscle cells and commonly used as an atherosclerosis marker, are increased in GHD patients compared to healthy controls and are brought within normality range after $\mathrm{GH}$ replacement therapy [66]. Even the study by Joaquin $e t$ al. confirmed the increase of PAPP-A and CRP levels in GHD [66]; that work seems to suggest the existence of a causal mechanism between the reduction of IGF-1 levels and the increase of PAPP-A, also leading to hypothesize that PAPP-A could have a role in the development of atherogenic process of GHD [67] (Fig. 1).

\section{Cardiovascular complications}

\section{3.a Atherosclerosis}

GHD has been associated with an increase of atheromatic plaques in carotid and femoral artery at ultrasonographic evaluation, compared to healthy controls $[68,69]$. Other atheromatosis markers in GHD are represented by the increased intima media thickness and by a greater carotid and aortic stiffness [70].

At the beginning of the 2000s, the effect of GHD in the production of nitric oxide (NO) was also evaluated. The decreased systemic synthesis of NO in GHD patients has been demonstrated [71]. This seems to be due to the direct effect of IGF-1 in stimulating NO synthesis in the endothelial cell [72]. In fact, in vitro studies demonstrated that endothelial cell has IGF-1 receptors, which are able to directly mediate NO synthesis, thus modulating vessel tone [72]. GHD related IGF-1 decrease is related to a decrease in arterial dilatation and to an increase of platelet aggregation, responsible for the impairment of endothelial and vasodilatatory function $[71,72]$. Recently, a study has reported an increase of asymmetric dimethylarginine (ADMA), an endogenous inhibitor of NO synthesis, that normalizes after GH therapy $[73,74]$.

\section{3.b Cardiac function and morphology}

Young adults GHD patients have a reduction of left ventricular (LV) mass and ejection fraction and an abnormal diastolic filling pattern. In this regard, some Authors found a significant reduction of LV systolic function as well as a decrease of the posterior wall of LV and of interventricular septum [75]. One open study has evaluated the cardiac function of 14 GHD patients and 12 healthy controls by radionuclide scanning [76]. That study confirmed the reduction of LV ejection fraction and the impairment of cardiac function indexes. The 6 months GH replacement therapy ameliorated cardiac function with a significant improvement in left ventricular ejection fraction (from $53 \% \pm 9 \%$ to $59 \% \pm 9 \%, P$ $<0.01$ ) and in cardiac index (from $2.8 \pm 0.6$ to $3.3 \pm 0.8 \mathrm{~L} /$ $\mathrm{min} / \mathrm{m}^{2}, P<0.01$ ). In 2003 a meta-analysis reviewed sixteen trials ( 9 blinded and 7 open) considering 468 patients who belonged to different populations and who were being treated with different GH dosages and duration of therapy; significant positive effects of $\mathrm{GH}$ on cardiac parameters assessed by echocardiography were evident. In particular, LV mass increased by 10.8 (standard deviation: 9.3) g $(P=0.02)$; similarly interventricular septum thickness increased by $0.28 \mathrm{~mm}(P<0.001)$ and LV posterior wall by $0.98 \mathrm{~mm}(P=0.05)$, confirming the effectiveness of GH replacement therapy on cardiac morphology [77]. Also, Giustina et al. demonstrated that $\mathrm{GH}$ has acute functional effects on the heart in patients with congestive heart failure (CHF), including both an increase in myocardial contractility and a decrease in vascular resistances, and among patients with CHF, those with low baseline IGF-1 are likely to have fewer beneficial effects from $\mathrm{GH}$ infusion [78]. However, a recent study did not show a significant increase of cardiac mass and function at different $\mathrm{GH}$ dosages therapies [79].

On the other hand, at cellular level, GH administration seems to improve cardiac function by the IGF-1 mediated calcium-sensitizing effects on myofilaments $[80,81]$.

\section{3.c Mortality and cardiovascular events in adult GHD}

Since the beginning of 1990s, several retrospective studies have demonstrated the relationship between hypopituitarism and the increase of cardiovascular risk, especially in women, with the increase of mortality associated with cardiovascular disease, specifically 
cerebrovascular [5, 82-87]. In a study Stochholm et al. demonstrated a morbidity increase in GHD, for both sexes, due to several risk factors such as the impaired metabolic profile [88]; recently, a work by van Bunderen et al. showed an increase of mortality for cardiovascular diseases in GHD women who were undergoing GH replacement therapy [89]. These data could also suggest that, in women, the association of GHD with an untreated estrogenic deficit could increase the risk of cardiovascular disease and, as a result, mortality [89].

More recent studies have evaluated the association in untreated GHD between the reduced levels of IGF-1 and the presence of coronary calcium deposits [90]. Computed tomography is useful to radiographically identify calcium deposits and has been recently validated as a reliable tool in order to estimate risk of developing coronary disease [91].

On the other hand, data about the impact of GH replacement therapy on the reduction of cardiovascular morbidity and mortality are still lacking. Several works have demonstrated the efficacy of GH replacement therapy in decreasing cardiovascular risk [85, 92, 93], but further controlled clinical trials will be necessary. In view of the worse cardiovascular risk factor and greater mortality of GHD women compared to men [94], the possible sex-related effect of GH replacement therapy on mortality in women has been assessed. Benefits of GH replacement therapy in terms of mortality seemed to be lower than the ones evident in men, probably because lower levels of IGF-1 and lean mass were achieved in women [1]. Hoffman et $a l$. demonstrated that hormone therapy in women needs to be specifically titrated and the different response in IGF-1 production results in a lower improvement of lipid profile and fat mass in women than in men [44]. These data show that premenopausal women are somehow resistant to the effects of GH replacement therapy, probably because sex hormones, especially estrogens, can influence the action of GH on IGF-1 production.

\section{Remarks}

Some peculiar populations require a few specific remarks.

\section{4. a Elderly GHD}

The age-related decline of GH/IGF-1 axis activity, also designated as "somatopause", is believed to be involved in the age-associated body composition change, such as decreased lean body, increased body fat and decreased muscle mass, thus mimicking the GHD clinical picture [95]. Mechanisms implicated in this process are mainly represented by changes in hypothalamic neuropeptides and neurotransmitters, leading to decreased GHRH secretion, and somatostatin hypersecretion [95].

Elderly GHD patients usually have a worse cardiovascular risk profile than the younger patients. In fact, two works reported higher prevalence of diabetes mellitus, coronary heart disease, stroke and history of hypertension in older individuals ( $>65$ years) as well as higher values of blood pressure $[96,97]$. This is likely explained by the positive correlation of blood pressure, cholesterol and LDL cholesterol levels with age in these patients [96, 97].

In this specific cohort of patients, GH replacement therapy positively and unequivocally affects total and LDL cholesterol levels, whereas it does not improve plasma triglyceride levels [98]. Controversy exists on the effects of the therapy on other cardiovascular risk factors, including insulin, HDL cholesterol, blood pressure and body composition [98]. Only one study evaluated the effects of replacement therapy on cardiac noninvasive structural and functional parameters in elderly GH deficient patients and reported non significant changes after 12 months [99].

\section{4.b GHD after treatment of acromegaly (acroGHD)}

GHD may also occur in adults with cured acromegaly [100]. This can happen in some medically treated patients, mainly when pegvisomant is used, or after neurosurgery or irradiation treatment. It can be hypothesized that, in acroGHD, the long-term effects of acromegaly on insulin resistance and hypertension could combine with similar ones from GHD, thus resulting in a further increased cardiovascular risk. Also, the acromegaly-related cardiac abnormalities could worsen after the development of GHD [101]. However, clinical studies do not fully confirm these theoretical hypotheses, as they found a BMI slightly increased [102-104] or, even, similar [105-108] in acroGHD compared to GHD and acromegalic populations. At the same time, while one work reported that acroGHD patients were more hypertensive, dyslipidemic, and diabetic than GHD subjects [109], other Authors pointed out a comparable prevalence of glucose abnormalities and dyslipidemia, as well as a similar amount of body fat and lean mass between acroGHD and ref- 
erence GHD groups [110]. It must however be highlighted that Feldt-Rasmussen and colleagues showed that acroGHD patients have a significantly higher prevalence of stroke compared to GHD of other etiologies [111]. As far as GH replacement therapy is concerned, evidence suggests that, in acroGHD, it achieves significant improvements of body composition (mainly body fat), CRP and lipid profile (especially LDL cholesterol) generally after 1 year [101]. However, as Tritos et al. found that cardiovascular mortality was increased in the acroGHD group compared with the GHD reference populations [100], a prudent approach is recommended in considering GH replacement in acroGHD patients with elevated cardiovascular risk [101].

\section{Safety and cost effectiveness of long-term use of GH therapy}

Safety issues related to the long-term use of GH therapy mainly regard the increased frequency of diabetes mellitus and the possible effects on the progression of the underlying tumour causing GHD as well as on de novo neoplasia. However, GH replacement therapy seems to be safe. In fact, prevalence of diabetes mellitus among adult patients with GH replacement seems to be related to classical risk factors for diabetes mellitus, such as BMI and age, and it is probably not increased by GH treatment [112]. As far as the oncological risk is concerned, it does not seem to be increased in the treated subjects [112]. Also, longterm GH replacement in adults is not associated with an additional increased risk of vascular disease and mortality [112].

Recombinant human GH is more expensive than conventional pituitary hormone replacement therapies, such as corticosteroids, sex steroids and thyroxine. However, few data are available on the cost effectiveness of GH replacement therapy. In this regard, hypopituitary patients with untreated GHD have been shown to have a higher cost to society in terms of lost production and medical consumption [113]. Verhelst and colleagues observed a decreased number of sick days after replacement therapy, from 12 days at baseline to 7 days in 6 months of therapy and to 3 days in 24 months of therapy [114]. More recently, a specific study on this subject demonstrated that GH therapy is a cost-effective therapy in Sweden when considering morbidity and mortality associated with GHD and the impact on quality of life [115].

\section{Conclusions}

GHD is able to increase cardiovascular risk by influencing the prevalence of well-known risk factors such as central obesity, the impaired lipid and glucose profile and other less-known risk factors such as proinflammatory cytokines, endothelial dysfunction and oxidative stress. Replacement GH therapy has been proven to be beneficial in many studies. However, since available data are limited and not always consistent, the long-term cardiovascular efficacy of GH replacement remains an issue which deserves future attention.

\section{Disclosure}

All authors report no conflicts of interest related to this study. No external funding, apart from the support of the authors' institution, was available for this study.

\section{References}

1. Gola M, Bonadonna S, Doga M, Giustina A (2005) Clinical review: growth hormone and cardiovascular risk factors. J Clin Endocrinol Metab 90: 1864-1870.

2. Colao A, Di Somma C, Pivonello R, Loche S, Aimaretti $\mathrm{G}$, et al. (1999) Bone loss is correlated to the severity of growth hormone deficiency in adult patients with hypopituitarism. J Clin Endocrinol Metab 84: 1919-1924.

3. Olczyk J, Kokoszko A, Lewiński A, KarbownikLewińska M (2010) Quality of life and exercise capacity in obesity and growth hormone deficiency. Neuro Endocrinol Lett 31: 700-707.

4. Cordido F, Garcia-Buela J, Sangiao-Alvarellos S,
Martinez T, Vidal O (2010) The decreased growth hormone response to growth hormone releasing hormone in obesity is associated to cardiometabolic risk factors. Mediators Inflamm 2010: 434562.

5. Lombardi G, Di Somma C, Grasso LF, Savanelli MC, Colao A, et al. (2012) The cardiovascular system in growth hormone excess and growth hormone deficiency. J Endocrinol Invest 35: 1021-1029.

6. Di Somma C, Pivonello R, Pizza G, De Rosa A, Lombardi G, et al. (2010) Prevalence of the metabolic syndrome in moderately-severely obese subjects with and without growth hormone deficiency. J Endocrinol 
Invest 33: 171-177.

7. Colao A, Di Somma C, Salerno M, Spinelli L, Orio F, et al. (2002) The cardiovascular risk of GH-deficient adolescents. J Clin Endocrinol Metab 87: 3650-3655.

8. Colao A, Marzullo P, Di Somma C, Lombardi G (2001) Growth hormone and the heart. Clin Endocrinol (Oxf) 54: 137-154.

9. Colao A, Cuocolo A, Di Somma C, Cerbone G, Della Morte AM, et al. (1999) Impaired cardiac performance in elderly patients with growth hormone deficiency. $J$ Clin Endocrinol Metab 84: 3950-3955.

10. Molitch ME, Clemmons DR, Malozowski S, Merriam GR, Vance ML, et al. (2011) Evaluation and Treatment of Adult Growth Hormone Deficiency: An Endocrine Society Clinical Practice Guideline. J Clin Endocrinol Metab 96: 1587-1609.

11. Biller BM, Samuels MH, Zagar A, Cook DM, Arafah BM, et al. (2002) Sensitivity and specificity of six tests for the diagnosis of adult GH deficiency. J Clin Endocrinol Metab 87: 2067-2079.

12. Corneli G, Di Somma C, Baldelli R, Rovere S, Gasco $\mathrm{V}$, et al. (2005) The cut-off limits of the GH response to GH-releasing hormone-arginine test related to body mass index. Eur J Endocrinol 153: 257-264.

13. Salomon F, Cuneo RC, Hesp R, Sonksen PH (1989) The effects of treatment with recombinant human growth hormone on body composition and metabolism in adults with growth hormone deficiency. $N$ Engl J Med 321: 1797-1803.

14. Abs R, Mattsson AF, Thunander M, Verhelst J, Góth MI, et al. (2013) Prevalence of diabetes mellitus in 6050 hypopituitary patients with adult-onset GH deficiency before GH replacement: a KIMS analysis. Eur $J$ Endocrinol 168: 297-305.

15. Ciresi A, Amato MC, Giordano C (2015) Reduction in insulin sensitivity and inadequate $\beta$-cell capacity to counteract the increase in insulin resistance in children with idiopathic growth hormone deficiency during 12 months of growth hormone treatment. J Endocrinol Invest 38: 351-359.

16. Cordoba-Chacon J, Gahete MD, McGuinness OP, Kineman RD (2014) Differential impact of selective GH deficiency and endogenous GH excess on insulinmediated actions in muscle and liver of male mice. $\mathrm{Am}$ J Physiol Endocrinol Metab 307: E928-E934.

17. Bramnert M, Segerlantz M, Laurila E, Daugaard JR, Manhem P, et al. (2003) Growth hormone replacement therapy induces insulin resistance by activating the glucose-fatty acid cycle. J Clin Endocrinol Metab 88: 1455-1463.

18. Boguszewski CL, Meister LH, Zaninelli DC, Radominski RB (2005) One year of GH replacement therapy with a fixed low-dose regimen improves body composition, bone mineral density and lipid profile of GH-deficient adults. Eur J Endocrinol 152: 67-75.
19. Spina LD, Soares DV, Brasil RR, da Silva EM, Lobo PM, et al. (2004) Glucose metabolism and visceral fat in GH deficient adults: 1 year of GH replacement. Growth Horm IGF Res 14: 45-51.

20. Cenci MC, Conceição FL, Soares DV, Spina LD, Brasil RR, et al. (2008) Impact of 5 years of growth hormone replacement therapy on cardiovascular risk factors in growth hormone-deficient adults. Metabolism 57: 121129.

21. Roemmler J, Kuenkler M, Schneider HJ, Dieterle C, Schopohl J (2010) Comparison of glucose and lipid metabolism and bone mineralization in patients with growth hormone deficiency with and without long-term growth hormone replacement. Metabolism 59: 350358.

22. Elbornsson M, Gotherstrom G, Bosæus I, Bengtsson BÅ, Johannsson G, et al. (2013) Fifteen years of GH replacement improves body composition and cardiovascular risk factors. Eur J Endocrinol 168: 745-753.

23. Gazzaruso C, Gola M, Karamouzis I, Giubbini R, Giustina A (2014) Cardiovascular risk in adult patients with growth hormone (GH) deficiency and following substitution with GH-an update. J Clin Endocrinol Metab 99: 18-29.

24. Haffner SM, D’Agostino R Jr, Mykkänen L, Tracy R, Howard B, et al. (1999) Insulin sensitivity in subjects with type 2 diabetes. Relationship to cardiovascular risk factors: the Insulin Resistance Atherosclerosis Study. Diabetes Care 22: 562-568.

25. Ross R (1986) The pathogenesis of atherosclerosis -an update. N Engl J Med 314: 488-500

26. Newman CB, Frisch KA, Rosenzweig B, Roubenoff R, Rey M, et al. (2011) Moderate doses of hGH (0.64 $\mathrm{mg} / \mathrm{d}$ ) improve lipids but not cardiovascular function in GH-deficient adults with normal baseline cardiac function. J Clin Endocrinol Metab 96: 122-132.

27. Cuneo RC, Salomon F, Watts GP, Hesp R, Sonsken PH (1993) Growth hormone treatment improves serum lipids and lipoproteins in adults with growth hormone deficiency. Metabolism 42: 1519-1523.

28. al-Shoumer KA, Cox KH, Hughes CL, Richmond W, Johnston DG (1997) Fasting and postprandial lipid abnormalities in hypopituitary women receiving conventional replacement therapy. J Clin Endocrinol Metab 82: 2653-2659.

29. Abdu TA, Neary R, Elhadd TA, Akber M, Clayton RN (2001) Coronary risk in growth hormone deficient hypopituitary adults: increased predicted risk is due largely to lipid profile abnormalities. Clin Endocrinol (Oxf) 55: 209-216.

30. Rizzo M, Trepp R, Berneis K, Christ ER (2007) Atherogenic lipoprotein phenotype and low-density lipoprotein size and subclasses in patients with growth hormone deficiency before and after short-term replacement therapy. Eur J Endocrinol 156: 361-367. 
31. Muller AF, Leebeek FWG, Janssen JAMJL, Lamberts SWJ, Hofland L, et al. (2001) Acute effect of pegvisomant on cardiovascular risk markers in healthy men: implications for the pathogenesis of atherosclerosis in GH deficiency. J Clin Endocrinol Metab 86: 5165 5171.

32. Froesch ER, Hussain M (1993) IGFs: function and clinical importance 5 Therapeutic potential of rhIGF-I in diabetes and conditions of insulin resistance. $J$ Intern Med 234: 561-570.

33. Janssen JA, Stolk RP, Pols HA, Grobbee DE, Lamberts SW (1998) Serum total IGF-1, free IGF-1, and IGFBP-1 levels in an elderly population: relation to cardiovascular risk factors and disease. Arterioscler Thromb Vasc Biol 18: 277-282.

34. Götherström G, Svensson J, Koranyi J, Alpsten M, Bosaeus I, et al. (2001) A prospective study of 5 years of GH replacement therapy in GH-deficient adults: sustained effects on body composition, bone mass, and metabolic indices. J Clin Endocrinol Metab 86: 4657 4665 .

35. Svensson J, Fowelin J, Landin K, Bengtsson BA, Johansson JO (2002) Effects of seven years of GH-replacement therapy on insulin sensitivity in GH-deficient adults. J Clin Endocrinol Metab 87: 2121-2127.

36. van der Klaauw AA, Romijn JA, Biermasz NR, Smit JW, van Doorn J, et al. (2006) Sustained effects of recombinant $\mathrm{GH}$ replacement after 7 years of treatment in adults with GH deficiency. Eur $J$ Endocrinol 155: 701-708.

37. Maison P, Griffin S, Nicoue-Beglah M, Haddad N, Balkau B, et al. (2004) Impact of growth hormone $(\mathrm{GH})$ treatment on cardiovascular risk factors in GH-deficient adults: a Meta analysis of Blinded, Randomized, Placebo-Controlled Trials. J Clin Endocrinol Metab 89: 2192-2199.

38. Chaves VE, Jùnior FM, Bertolini GL (2013) The metabolic effects of growth hormone in adipose tissue. Endocrine 44: 293-302.

39. Amato G, Mazziotti G, Di Somma C, Lalli E, De Felice $\mathrm{G}$, et al. (2000) Recombinant growth hormone (GH) therapy in GH-deficient adults: a long-term controlled study on daily versus thrice weekly injections. J Clin Endocrinol Metab 85: 3720-3725.

40. Hazem A, Elamin MB, Bancos I, Malaga G, Prutsky G, et al. (2012) Body composition and quality of life in adults treated with GH therapy: a systematic review and meta-analysis. Eur J Endocrinol 166: 13-20.

41. Attanasio AF, Mo D, Erfurth EM, Tan M, Ho KY, et al. (2010) Prevalence of metabolic syndrome in adult hypopituitary growth hormone GH deficient patients before and after GH replacement. J Clin Endocrinol Metab 95: $74-81$.

42. Ukropec J, Penesová A, Skopková M, Pura M, Vlcek
M, et al. (2008) Adipokine protein expression pattern in growth hormone deficiency predisposes to the increased fat cell size and the whole body metabolic derangements. J Clin Endocrinol Metab 93: 2255-2262.

43. Gomes Santos E, Salvatori R, Ferrao TO, Oliveira CR, Diniz RD, et al. (2014) Increased Visceral Adiposity and Cortisol to Cortisone Ratio in Adults With Congenital Lifetime Isolated GH Deficiency. J Clin Endocrinol Metab 99: 3285-3289.

44. Hoffman AR, Kuntze JE, Baptista J, Baum HB, Baumann GP, et al. (2004) Growth hormone (GH) replacement therapy in adult-onset GH deficiency: effects on body composition in men and women in a double-blind, randomized, placebo-controlled trial. $J$ Clin Endocrinol Metab 89: 2048-2056.

45. Franco C, Johannsson G, Bengtsson BA, Svensson J (2006) Baseline characteristics and effects of growth hormone therapy over two years in younger and elderly adults with adult onset GH deficiency. J Clin Endocrinol Metab 91: 4408-4414.

46. Fernholm R, Bramnert M, Hagg E, Hilding A, Baylink DJ, et al. (2000) Growth hormone replacement therapy improves body composition and increases bone metabolism in elderly patients with pituitary disease. J Clin Endocrinol Metab 85: 4104-4112.

47. Tanriverdi F, Unluhizarci K, Kula M, Guven M, Bayram F, et al. (2005) Effects of 18-month of growth hormone (GH) replacement therapy in patients with Sheehan's syndrome. Growth Horm IGF Res 15: 231-237.

48. Odden MC, Shlipak MG, Whitson HE, Katz R, Kearney PM, et al. (2014) Risk factors for cardiovascular disease across the spectrum of older age: The Cardiovascular Health Study. Atherosclerosis 237: 336-342.

49. McCallum RW, Sainsbury CA, Spiers A, Dominiczak AF, Petrie JR, et al. (2005) Growth hormone replacement reduces $\mathrm{C}$-reactive protein and large artery stiffness but does not alter endothelial function in patients with adult growth hormone deficiency. Clin Endocrinol (Oxf) 62: 473-479.

50. Sesmilo G, Miller KK, Hayden D, Klibanski A (2001) Inflammatory cardiovascular risk markers in women with hypopituitarism. J Clin Endocrinol Metab 86: 5774-5781.

51. Deepak D, Daousi C, Javadpour M, Clark D, Perry Y, et al. (2010) The influence of growth hormone replacement on peripheral inflammatory and cardiovascular risk markers in adults with severe growth hormone deficiency. Growth Horm IGF Res 20: 220-225.

52. Libby P (2012) Inflammation in atherosclerosis. Arterioscler Thromb Vasc Biol 32: 2045-2051.

53. Wong BW, Meredith A, Lin D, McManus BM (2012) The biological role of inflammation in atherosclerosis. Can J Cardiol 28: 631-641.

54. Sahin-Efe A, Katsikeris F, Mantzoros CS (2012) Advances in adipokines. Metabolism 61: 1659-1665. 
55. Serri O, St-Jacques P, Sartippour M, Renier G (1999) Alterations of monocyte function in patients with growth hormone (GH) deficiency: effect of substitutive GH therapy. $J$ Clin Endocrinol Metab 84: 58-63.

56. Andiran N, Yordam N (2007) TNF-alpha levels in children with growth hormone deficiency and the effect of long-term growth hormone replacement therapy. Growth Horm IGF Res 17: 149-153.

57. Miyakawa $\mathrm{M}$, Tsushima $\mathrm{T}$, Murakami $\mathrm{H}$, Isozaki $\mathrm{O}$, Demura H, et al. (1998) Effect of growth hormone (GH) on serum concentrations of leptin: study in patients with acromegaly and GH deficiency. J Clin Endocrinol Metab 83: 3476-3479.

58. Fisker S, Vahl N, Hansen TB, Jørgensen JO, Hagen C, et al. (1997) Serum leptin is increased in growth hormone-deficient adults: relationship to body composition and effects of placebo-controlled growth hormone therapy for 1 year. Metabolism 46: 812-817.

59. López-Siguero JP, López-Canti LF, Espino R, Caro E, Fernández-García JM, et al. (2011) Effect of recombinant growth hormone on leptin, adiponectin, resistin, interleukin-6, tumor necrosis factor-and ghrelin levels in growth hormone-deficient children. $J$ Endocrinol Invest 34: 300-306.

60. Colao A, Di Somma C, Pivonello R, Cuocolo A, Spinelli L, et al. (2002) The cardiovascular risk of adult GH deficiency (GHD) improved after GH replacement and worsened in untreated GHD: a 12-month prospective study. J Clin Endocrinol Metab 87:1088-1093.

61. Kvasnicka J, Marek J, Kvasnicka T, Weiss V, Marková $M$, et al. (2000) Increase of adhesion molecules, fibrinogen, type-1 plasminogen activator inhibitor and orosomucoid in growth hormone (GH) deficient adults and their modulation by recombinant human GH replacement. Clin Endocrinol (Oxf) 52: 543-548.

62. Smith JC, Lane HA, Lewis J, Dann S, Goodfellow J, et al. (2003) Endothelial function and coagulant factors in growth hormone-treated hypopituitary adults receiving desmopressin. J Clin Endocrinol Metab 88: 2152-2156.

63. Johansson JO, Landin K, Johannsson G, Tengborn L, Bengtsson BA (1996) Long-term treatment with growth hormone decreases plasminogen activator inhibitor-1 and tissue plasminogen activator in growth hormonedeficient adults. Thromb Haemost 76: 422- 428.

64. Miljic D, Miljic P, Doknic M, Pekic S, Stojanovic M, et al. (2013) Growth hormone replacement normalizes impaired fibrinolysis: new insights into endothelial dysfunction in patients with hypopituitarism and growth hormone deficiency. Growth Horm IGF Res 23: 243248.

65. Cakir I, Tanriverdi F, Karaca Z, Kaynar L, Eser B, et al. (2012) Evaluation of coagulation and fibrinolytic parameters in adult onset GH deficiency and the effects of GH replacement therapy: a placebo controlled study. Growth Horm IGF Res 22: 17-21.
66. Joaquin C, Aguilera E, Granada ML, Pastor MC, Salinas I, et al. (2008) Effects of GH treatment in GH-deficient adults on adiponectin, leptin and pregnancy-associated plasma protein-A. Eur J Endocrinol 158: 483-490.

67. Li L, Ren W, Li J, Liu J, Wang L, et al. (2012) Increase in serum pregnancy-associated plasma protein-A is correlated with increase in cardiovascular risk factors in adult patients with growth hormone deficiency. Endocrine 42: 375-381.

68. Markussis V, Beshyah SA, Fisher C, Sharp P, Nicolaides AN, et al. (1992) Detection of premature atherosclerosis by high-resolution ultrasonography in symptom-free hypopituitary adults. Lancet 340: 1188-1192.

69. Colao A, Di Somma C, Spiezia S, Savastano S, Rota F, et al. (2008) Growth hormone treatment on atherosclerosis: results of a 5-year open, prospective, controlled study in male patients with severe growth hormone deficiency. J Clin Endocrinol Metab 93: 3416-3424.

70. Markussis V, Beshyah SA, Fisher C, Parker KH, Nicolaides AN, et al. (1997) Abnormal carotid arterial wall dynamics in symptom free hypopituitary adults. Eur J Endocrinol 136: 157-164.

71. Boger RH, Skamira C, Bode-Boger SM, Brabant G, von zur Muhlen A, et al. (1996) Nitric oxide may mediate the hemodynamic effects of recombinant growth hormone in patients with acquired growth hormone deficiency. A double-blind, placebo-controlled study. J Clin Invest 98: 2706-2713.

72. Tsukahara H, Gordienko DV, Tonshoff B, Gelato MC, Goligorsky MS (1994) Direct demonstration of insulinlike growth factor-1-induced nitric oxide production by endothelial cells. Kidney Int 45: 598-604.

73. Setola E, Monti LD, Lanzi R, Lucotti P, Losa M, et al. (2008) Effects of growth hormone treatment on arginine to asymmetric dimethylarginine ratio and endothelial function in patients with growth hormone deficiency. Metabolism 57: 1685-1690.

74. Krzyzanowska K, Mittermayer F, Schnack C, Hofer M, Wolzt M, et al. (2005) Circulating ADMA concentrations are elevated in hypopituitary adults with and without growth hormone deficiency. Eur J Clin Invest 35: 208-213.

75. Amato G, Carella C, Fazio S, La Montagna G, Cittadini A, et al. (1993) Body composition, bone metabolism and heart structure and function in growth hormone (GH)-deficient adults before and after GH replacement therapy at low doses. J Clin Endocrinol Metab 77: 1671-1676.

76. Cuocolo A, Nicolai E, Colao A, Longobardi S, Cardei $S$, et al. (1996) Improved left ventricular function after growth hormone replacement in patients with hypopituitarism: assessment with radionuclide angiography. Eur J Nucl Med 23: 390-394.

77. Maison P, Chanson P (2003) Cardiac effects of growth hormone in adults with growth hormone deficiency: a 
meta-analysis. Circulation 108: 2648-2652.

78. Giustina A, Volterrani M, Manelli F, Desenzani P, Poiesi C, et al. (1999) Endocrine predictors of acute hemodynamic effects of growth hormone in congestive heart failure. Am Heart J 137: 1035-1043.

79. Andreassen M, Faber J, Kjaer A, Petersen CL, Kristensen LØ (2011) Cardiac function in growth hormone deficient patients before and after 1 year with replacement therapy: a magnetic resonance imaging study. Pituitary 14: 1-10.

80. Cittadini A, Marra AM, Arcopinto M, Bobbio E, Salzano A, et al. (2013) Growth hormone replacement delays the progression of chronic heart failure combined with growth hormone deficiency: an extension of a randomized controlled single-blind study. JACC Heart Fail 1: 325-330.

81. Wang M, Tsai B, Brown JW, Meldrum DR (2003) Insulin-like growth factor-1 in myocardial tissue: interaction with tumor necrosis factor. Crit Care 7: 417-419.

82. Rosén T, Bengtsson BA (1990) Premature mortality due to cardiovascular disease in hypopituitarism. Lancet 336: 285-288.

83. Bates AS, Van't Hoff W, Jones PJ, Clayton RN (1996) The effect of hypopituitarism on life expectancy. J Clin Endocrinol Metab 81: 1169-1172.

84. Bülow B, Hagmar L, Mikoczy Z, Nordström CH, Erfurth EM (1997) Increased cerebrovascular mortality in patients with hypopituitarism. Clin Endocrinol (Oxf) 46: $75-81$.

85. Svensson J, Bengtsson BA, Rosén T, Odén A, Johannsson G (2004) Malignant disease and cardiovascular morbidity in hypopituitary adults with or without growth hormone replacement therapy. J Clin Endocrinol Metab 89: 3306-3312.

86. Tomlinson JW, Holden N, Hills RK, Wheatley K, Clayton RN, et al. (2001) Association between premature mortality and hypopituitarism. West Midlands Prospective Hypopituitary Study Group. Lancet 357: 425-431.

87. Burman P, Mattsson AF, Johannsson G, Höybye C, Holmer H, et al. (2013) Deaths among adult patients with hypopituitarism: hypocortisolism during acute stress, and de novo malignant brain tumors contribute to an increased mortality. J Clin Endocrinol Metab 98: 1466-1475.

88. Stochholm K, Laursen T, Green A, Laurberg P, Andersen M, et al. (2008) Morbidity and GH deficiency: a nationwide study. Eur J Endocrinol 158: 447-457.

89. van Bunderen CC, van Nieuwpoort IC, Arwert LI, Heymans MW, Franken AA, et al. (2011) Does growth hormone replacement therapy reduce mortality in adults with growth hormone deficiency? Data from the Dutch National Registry of Growth Hormone Treatment in adults. J Clin Endocrinol Metab 96: 3151-3159.

90. Cannavò S, Marini F, Curtò L, Torre ML, de Gregorio
C, et al. (2011) High prevalence of coronary calcifications and increased risk for coronary heart disease in adults with growth hormone deficiency. $J$ Endocrinol Invest 34: 32-37.

91. Vliegenthart R, Morris PB (2012) Computed tomography coronary artery calcium scoring: review of evidence base and cost-effectiveness in cardiovascular risk prediction. J Thorac Imaging 27: 296-303.

92. Schneider HJ, Klotsche J, Wittchen HU, Stalla GK, Schopohl J, et al. (2011) Effects of growth hormone replacement within the KIMS survey on estimated cardiovascular risk and predictors of risk reduction in patients with growth hormone deficiency. Clin Endocrinol (Oxf) 75: 825-830.

93. Monson JP (2003) Long-term experience with GH replacement therapy: efficacy and safety. Eur $J$ Endocrinol 148 Suppl 2: S9 -S14.

94. Bulow B, Hagmar L, Eskilsson J, Erfurth EM (2000) Hypopituitary females have a high incidence of cardiovascular morbidity and an increased prevalence of cardiovascular risk factors. $J$ Clin Endocrinol Metab 85: 574-584.

95. Giordano R, Bonelli L, Marinazzo E, Ghigo E, Arvat E (2008) Growth hormone treatment in human ageing: benefits and risks. Hormones (Athens) 7: 133-139.

96. Monson JP, Abs R, Bengtsson BA, Bennmarker H, Feldt-Rasmussen U, et al. (2000) Growth hormone deficiency and replacement in elderly hypopituitary adults. KIMS Study Group and the KIMS International Board. Pharmacia and Upjohn International Metabolic Database. Clin Endocrinol (Oxf) 53: 281-289.

97. Feldt-Rasmussen U, Wilton P, Jonsson P; KIMS Study Group; KIMS International Board (2004) Aspects of growth hormone deficiency and replacement in elderly hypopituitary adults. Growth Horm IGF Res 14 Suppl A: S51-58.

98. Kokshoorn NE, Biermasz NR, Roelfsema F, Smit JW, Pereira AM, et al. (2011) GH replacement therapy in elderly GH-deficient patients: a systematic review. Eur $J$ Endocrinol 164: 657-665.

99. Elgzyri T, Castenfors J, Hägg E, Backman C, Thorén M, et al. (2004) The effects of GH replacement therapy on cardiac morphology and function, exercise capacity and serum lipids in elderly patients with GH deficiency. Clin Endocrinol (Oxf) 61: 113-122.

100. Tritos NA, Johannsson G, Korbonits M, Miller KK, Feldt-Rasmussen U, et al. (2014) Effects of long-term growth hormone replacement in adults with growth hormone deficiency following cure of acromegaly: a KIMS analysis. J Clin Endocrinol Metab 99: 2018-2029.

101. Mazziotti G, Marzullo P, Doga M, Aimaretti G, Giustina A (2015) Growth hormone deficiency in treated acromegaly. Trends Endocrinol Metab 26: 11-21.

102. Pekic S, Doknic M, Miljic D, Joksimovic M, Glodic J, et al. (2006) Ghrelin test for the assessment of GH status 
in successfully treated patients with acromegaly. Eur $J$ Endocrinol 154: 659-666.

103. van der Klaauw AA, Bax JJ, Bleeker GB, Holman ER, Delgado V, et al. (2008) Cardiac manifestations of GH deficiency after treatment for acromegaly: a comparison to patients with biochemical remission and controls. Eur J Endocrinol 159: 705-712.

104. van Bunderen CC, van Varsseveld NC, Heymans MW, Franken AA, Koppeschaar HP, et al. (2014) Effect of long-term GH replacement therapy on cardiovascular outcomes in GH-deficient patients previously treated for acromegaly: a sub-analysis from the Dutch National Registry of Growth Hormone Treatment in Adults. Eur $J$ Endocrinol 171:717-726.

105. Yamada S, Fukuhara N, Nishioka H, Takeshita A, Suzuki H, et al. (2011) GH deficiency in patients after cure of acromegaly by surgery alone. Eur J Endocrinol 165:873-879.

106. Giavoli C, Profka E, Verrua E, Ronchi CL, Ferrante E, et al. (2012) GH replacement improves quality of life and metabolic parameters in cured acromegalic patients with growth hormone deficiency. J Clin Endocrinol Metab 97:3983-3988.

107. Lin E, Wexler TL, Nachtigall L, Tritos N, Swearingen B, et al. (2012) Effects of growth hormone deficiency on body composition and biomarkers of cardiovascular risk after definitive therapy for acromegaly. Clin Endocrinol (Oxf) 77:430-438.

108. Wexler TL, Durst R, McCarty D, Picard MH, Gunnell L, et al. (2010) Growth hormone status predicts left ventricular mass in patients after cure of acromegaly.
Growth Horm IGF Res 20:333-337.

109. Norrman LL, Johannsson G, Sunnerhagen KS, Svensson $\mathrm{J}$ (2008) Baseline characteristics and the effects of two years of growth hormone (GH) replacement therapy in adults with GH deficiency previously treated for acromegaly. J Clin Endocrinol Metab 93:2531-2538.

110. Ronchi CL, Giavoli C, Ferrante E, Verrua E, Bergamaschi S, et al. (2009) Prevalence of GH deficiency in cured acromegalic patients: impact of different previous treatments. Eur J Endocrinol 161:37-42.

111. Feldt-Rasmussen U, Abs R, Bengtsson BA, Bennmarker $\mathrm{H}$, Bramnert M, et al. (2002) Growth hormone deficiency and replacement in hypopituitary patients previously treated for acromegaly or Cushing's disease. Eur $J$ Endocrinol 146:67-74.

112. Stochholm K, Johannsson G (2015) Reviewing the safety of GH replacement therapy in adults. Growth Horm IGF Res 25:149-157.

113. Hakkaart-van Roijen L, Beckers A, Stevenaert A, Rutten FF (1998) The burden of illness of hypopituitary adults with growth hormone deficiency. Pharmacoeconomics 14:395-403.

114. Verhelst J, Abs R, Vandeweghe M, Mockel J, Legros JJ, et al. (1997) Two years of replacement therapy in adults with growth hormone deficiency. Clin Endocrinol (Oxf) 47:485-94.

115. Bolin K, Sandin R, Koltowska-Häggström M, Loftus J, Prütz C, et al. (2013) The cost-effectiveness of growth hormone replacement therapy (Genotropin $®$ ) in hypopituitary adults in Sweden. Cost Eff Resour Alloc 11:24. 